SELWYN MANNING is co-editor of Scoop and acting editor of Pacific Scoop.

\section{A challenge to the spook agencies' media spin}

Spinning Intelligence: Why Intelligence Needs the Media, Why the Media Needs Intelligence, by Robert Dover and Michael S. Goodman (eds). London, United Kingdom: C. Hurst \& Co, 2009, 263 pp. ISBN 978-1-85065-993-8 (hbk), 978-1-85065-994-5 (pbk).

CURSORY glance at how intel-
ligence agencies operate may suggest such entities contain themselves and the information they acquire within sealed silos, observing the outside world from a statutoryprotected vantage-point while refusing any reciprocal attention from the public whose interests they serve.

For those observing the function of these agencies from outside their mystique is often intensified due to an ignorance of security intelligence agencies, including the methods they use to acquire information, and suspicion about their motivations and the

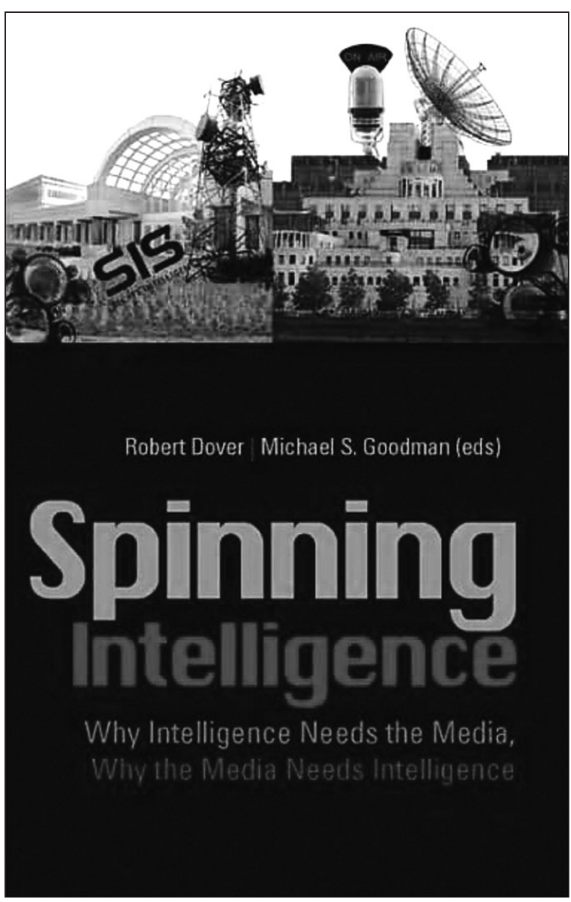

purpose of their resulting analysis.

The book Spinning Intelligence investigates this culture, the relationship that exists between security intelligence agencies and other institutions, and lays bare a solidly researched account that is as readable as it is a resource. The book explores whether intelligence agencies operate within a culture of accountability, giving special attention to the most powerful agencies in our post-millennium world.

A common test within the book considers how intelligence agencies and the media, or the Fourth Estate, 
are interrelated. It argues that while there is a symbiotic relationship between intelligence agencies and the media, this relationship often leaves the media in want of citable information. Consequently, the Fourth Estate is left subservient to those who hold, control, and manipulate classified official information.

Spinning Intelligence draws on the work of academics specialising in media studies, political science, and intelligence and security analysis. It structures its chapters in a subjectaligned logic that is deep in academic discourse while presenting the writers' thinking in an accessible and reader-friendly style.

It opens with an exploration of the relationship between globalisation and intelligence and cites research, focusing most significantly on the United States of America and the United Kingdom, as a foundation for its central argument: that intelligence agencies and the media do not lead separate existences but rather have an inter-dependent, and, at times, symbiotic relationship (p. 13).

For those interested in examining how intelligence agencies and the media inter-relate in the Pacific region, Spinning Intelligence is a valuable contribution that assists in identifying difference. Clearly, unlike their northern hemisphere counterparts, convention suggests South Pacific states are reticent to acknowledge they conduct an intelligence gathering role beyond their domestic borders. To do so would risk stressing inter-state relationships. However, it would be naïve to assume intelligence gathering does not go on. There is evidence that where crisis and insecurity occurs, such as in the months leading up to December 2006 when Fiji's elected government was under threat of being removed from office by its military, Australia and New Zealand's diplomatic posts were required to pass back to their executive governments information that assisted with foreign policy development. Both Australia's and New Zealand's prime ministers of the time had their operational staff report back on security and stability aspects of Fiji's military/governmental estrangement and to analyse what impact Fiji's instability would have on the personal security of the two prime ministers while attending the 2006 Pacific Islands Forum in Nadi. Also, at the 2006 Pacific Islands Forum, New Zealand Ministry of Foreign Affairs and Trade staff attended and recorded press conferences held between the Fourth Estate and Pacific state leaders.

However, in the South Pacific, there remains an information vacuum which, if filled would assist in 
understanding the relationship between security intelligence agencies and the Fourth Estate from both a domestic and outward-looking context. Again, in this regard Spinning Intelligence is valuable in demonstrating what is common practice in the northern hemisphere, and therefore provides a framework and methodology of how to test the function of disseminating intelligence information in the Pacific region.

In Spinning Intelligence, the writers take an historical approach to developing an understanding of how access to classified information (routinely identified as material high in the public, national, and international security interest) is affected by levels of political risk and security sensitivities (p.15).

The writers examine how today's democracies approach official information, how they classify it, how sensitivities over the classification of information intensify as cultures feel they are threatened, and become more security-conscious and riskaverse. They cite the post-Cold War period as an example of a time when classifications were relaxed, when, in the 1990s, the culture of security intelligence agencies shifted to embrace a more open-access policy to formerly classified top secret information. The writers also observe how, after the attacks on the World Trade Center in New York City on 11 September 2001, the open access culture reverted back to a guarded high-security condition (p. 27).

The book analyses how the attacks heralded in a new high security era that led the USA's Central Intelligence Agency and the UK's MI6 and MI5 to resort to clandestine surveillance of their own citizenry. It analyses how in the United States the George W. Bush administration employed draconian measures to protect classified information from becoming public, even when the information was high in the public interest. The writers argue that such methods included changes to state secret legislation in order to mask government methods of information gathering. This tougher legislation was used to intimidate journalists and officials including by prosecuting investigative journalists and their sources when re-classified secret information was brought to the public's attention, even when it was revealed in the public interest (p. 30).

Examples are given of how high-profile journalists were charged. James Risen of The New York Times was one of those indicted. In his reports, Risen had revealed how the US government's National Security Agency was intercepting, without 
warrant, international phone calls that originated or terminated in the United States (p. 30). Professional journalist organisations believed the strategy was designed by the state apparatus to intimidate journalists and deter their confidential sources from revealing information that was deemed too sensitive for public consumption (p. 31).

Spinning Intelligence also identifies how modern democracies, within a globalised intelligence context, are interconnected through alliance networks controlled by superpowers influenced by geopolitical events. It identifies where individual states are permitted access to levels of intelligence information and sharing, as determined by their respective classification level and importance to the overall alliance.

Spinning Intelligence is an important book in the security-intelligence sub-genre that evaluates the power imbalances between state executives and the Fourth Estate. The book lays bare how even in times of threat and war, intelligence organisations need the media so as to create a public culture that empowers a state to counter a perceived threat or enemy. In chapter 6, entitled 'All The Secrets That Are Fit To Print', writers Steve Hewitt and Scott Lucas investigate a contemporary history of how the Fourth Estate is manipulated by security agencies. Their account is a revelation that ought to compel all professional journalists to focus on how they, as representatives of the Fourth Estate and therefore the public, can remedy the imbalance and again challenge and critique these most powerful and important institutions. 